\title{
Construction of Physical Education Assessment System Based on Information Technology
}

\author{
Dachun Zhang ${ }^{1, \text { a }}$ \\ ${ }^{1}$ Physical Education Department of Heihe University, Heihe, Heilongjiang, China \\ ae-mail:zhangdachun2010@163.com
}

Keywords: Information Technology, Physical Education, Assessment System

\begin{abstract}
Physical Education evaluation is an important part of college education. There are many unreasonable in the current PE curriculum assessment system. One the fact that can not deny is that physical education curriculum evaluation has unwittingly fundamentally bound to live up the pace of college physical education reform and development. Therefore, building a learning assessment system to adapt to the quality of education is to achieve a fundamental change of college physical education inevitable requirement, but also the current study and resolve urgent issues. In order to deepen the teaching reform of college sports made useful suggestions, from the "Health First" idea, this article take sports courses evaluation purpose, content, methods and indicators of 1 to 2 colleges for the study of learning evaluation discuss reform of college physical education curriculum. In this paper, the status of PE Curriculum Assessment and problems of college are studed to determine the proportion of new university sports curriculum evaluation and presents a comprehensive course of study college sports score and a quantitative evaluation method proposed conduct college sports programs.
\end{abstract}

\section{Introduction}

In august 2004, the Ministry of Education states [1]: Given the current situation of college sports, colleges and universities must attach great importance to physical education curriculum reform, efforts to achieve lifelong sports college sports and the relative access, college students through physical education, at least two master motor skills, develop good exercise habits, physical exercise in healthy taste of quality of life. In teaching, we found that as an important part of teaching, physical education academic evaluation system reform lagged behind, did not do synchronized with the unification and content, methods, models and so on. Through investigation we have found that students do not like physical education is one of the important reasons to take the test (Table 1), which has seriously affected the quality of physical education and hinder the completion of the teaching goals. Therefore, a reasonable evaluation system of sports is imperative.

However, from a focus on "three basis" education to physical education and health education to the present, the ideas, methods and practices although the method has made significant progress throughout the course of teaching reform college sports,. but the true meaning of college sports from the requirements on the quality of education there is not a small distance. The new curriculum and college sports, where is the difference between traditional physical education, college sports programs to achieve what new goals, especially what kind of criteria used to evaluate teaching college sports results, evaluate what; these questions puzzled new sports in colleges and universities construction and development courses. Thus, there are practical significance on the establishment of a new physical education curriculum, while establishing a new physical education curriculum evaluation system. Only if evaluation function focus on the importance of motivation and development capabilities, based on the students, encouraging students to develop a comprehensive, giving each student equal conditions and opportunities, create a good space for development, in order to meet the requirements of quality education and innovative education, so that students get a good development for students to create the conditions for sustainable development, curriculum evaluation function from the screening and selection of the road towards the overall development of education for sustainable development is to foster the development of embodied human. 
Table 1 The reasons of students' dissatisfaction

\begin{tabular}{cccccccc}
\hline & $\begin{array}{c}\text { Time } \\
\text { table is } \\
\text { not } \\
\text { suitable }\end{array}$ & $\begin{array}{c}\text { Technology } \\
\text { is sample } \\
\text { and no new } \\
\text { information } \\
\text { can be } \\
\text { learned }\end{array}$ & $\begin{array}{c}\text { Technology } \\
\text { is hard }\end{array}$ & $\begin{array}{c}\text { Some } \\
\text { content is } \\
\text { not } \\
\text { satisfactory }\end{array}$ & $\begin{array}{c}\text { The } \\
\text { place is } \\
\text { not } \\
\text { suitable }\end{array}$ & $\begin{array}{c}\text { Cannot } \\
\text { increase } \\
\text { the } \\
\text { capability }\end{array}$ & $\begin{array}{c}\text { Others } \\
\text { to be } \\
\text { handle }\end{array}$ \\
\hline Number & 38 & 94 & 12 & 43 & 82 & 52 & 130 \\
Percentage(\%) & 22.4 & 55.3 & 7.1 & 25.3 & 48.2 & 30.6 & 76.5 \\
\hline
\end{tabular}

\section{The Evaluation Can Take the Role of Incentive System}

Through the evaluation, the students own physical condition, skills, attitudes, interpersonal aspects have a clear and correct understanding, encouraging students to participate in physical self-study and exercise. Students have self-awareness, the ability to self-education, self-training to develop good habits.

Through the evaluation of learning, on the one hand to allow students to demonstrate their strengths sports, on the other hand allow students to experience the learning experience and progress with the fun and joy of success, and enhance students' physical education learning self-confidence, help to improve initiative and enthusiasm of students to participate and learn both motor skills, and lay a solid foundation for lifelong physical. Provide students demonstrate their ability level, personalized opportunities and incentives and promoting progress and development of students [2].

By learning assessment, understand student learning and performance, as well as the degree of completion of learning objectives. It is not only to understand the students' physical condition and skills, but also to understand the behavior of students in learning activities. Not only does it require students to meet the standards, but should include the individual's level of effort, attention to individual differences, encouraging students to continue to better ourselves.

By learning assessment to determine student learning deficiencies exist, analyze the causes and to promote student learning and teacher education. For students in learning behaviors, attitudes, physical, skills and other aspects of the performance out of the problem, as well as lack of teachers teaching in the exposed, analyzed and summarized, efforts to improve teaching and learning and to promote the emergence of contradictions transformation, so that the disadvantages of IDS to improve the practical effect of PE teaching. Establish a rational, sound and scientific evaluation system for the development of students' physical, psychological, social and other aspects of adaptation can play "skillfully deflected the question" role. In a certain extent, the evaluation system is a kind of "incentives." Learning outcomes and process evaluation of teachers in the process of teaching physical education curriculum, and through feedback to grasp the magnitude of the situation of student learning progress and problems, in order to adjust teaching methods and programs to solve problems using a variety of methods and means mining greatest potential students to conduct a comprehensive, objective, true and accurate student assessment, evaluation of feedback from the physical education curriculum emphasis on results and the process of learning to pay attention, this evaluation can keep abreast of the students' learning process and the results, can find and solve problems, both real and reliable evaluation of students 'progress and attitudes in the learning process, and continue to inspire and encourage the enthusiasm of students, but also to fully develop the potential of students and improve students' practical abilities. 


\section{Selection and Evaluation Method of the Evaluating Content}

Consistent with the choice of a good curriculum goals, especially consistent evaluation of the content and assessment methods and the level of the target area of study is an important part of the evaluation system. According to the Ministry of Education to develop a "National Physical Education Curriculum Teaching Guidelines" spirit, in the actual teaching of feedback information, the purpose of the task required physical education curriculum and quality education, the World Health Organization definition of health, and the practice can be maneuverability, made the following evaluation contents and evaluation methods in five areas.

Physical Health Status. Including body shape, body function, physical fitness. Body shape as height, weight, physical function is the heart and lung function indices, fitness refers to the step experiment $(1000 \mathrm{~m}), 50 \mathrm{~m}$, standing long jump, sit-ups and other content. Assessment of physical health, we must first be evaluated to "Student Healthy Standard" as the basis of the actual situation, but also to focus on physical health of students ' progress. Students ' progress refers to the original physical health status changes compared with the current situation. This requires us to students during school physical fitness test, the data obtained is called raw data, after a period of study and training the measured results for the current achievements. Under normal circumstances, the two test items should be consistent. Including strength, coordination, endurance, flexibility and other projects. Test methods should be anchored to the original score, according to the laws of physical growth, present different growth rates, the growth rate worked out by the different scores to the current score of the base value, the current results with the original score to calculate the growth rate, the corresponding achievement of progress scores, adding up to the final score. Quantitative evaluation of the approach taken by the way [3].

Sports Basics. Including sports and sports basic theoretical knowledge of health care knowledge. Including the development of basic theoretical knowledge of sports history and modern sport, the basic principles of competition rules and exercise techniques for each sport. Physical health care knowledge, including knowledge of basic health, prevention and treatment of common movement disorders and sports injuries, and basic knowledge of sports and health guidance, the basic structure and physiological basis of human knowledge, mental health and other knowledge. Assessment methods are mainly teachers and students participating, take written, oral, small papers and other forms of evaluation.

Sports Basic Skills. Including technical skill level and athletic ability in practice. Technical skill level combined with personal characteristics that students make full use of their own conditions to master technical skills sport, learn two sports skills. Sports practice refers to the ability to master the motor skills to be used in the actual sports activities, and use it as the basic method of physical exercise performed. Assessment methods based teacher evaluation, student self-assessment, peer assessment combining the process evaluation and outcome evaluation together.

Evaluation of Learning Attitude. To make the school Physical Education and Lifelong Physical relative access, foster students' correct understanding of physical education and health, and to form a correct and positive attitude towards sport, so the learning attitude as an important achievement assessment. Content is based, can take the initiative and consciously participate in sports learning and training, which includes curricular and extra-curricular. Attendance in class, the ability to think proactively in order to achieve goals and repeated practice, can seriously accept the teacher's guidance; extracurricular that students usually participate in collective sports, and weekly participation in sport behavior and habits. Assessment Methods instructor supervision, evaluation process based, peer assessment approach taken by students [4].

Affective Expression and the Spirit of Cooperation. Improve mental health and social adaptability is one of the important goals of physical education. Mainly for evaluation, mental health, the ability to overcome the learning process and to overcome shyness, low self-esteem, build self-confidence; able to overcome all difficulties and obstacles, keep learning and exercise; social adaptability, the ability to respect and understand others and exhibit good interpersonal skills and the spirit of cooperation, and the courage to take responsibility; ability to comply with the rules, 
respect the referee; can be humble in victory, defeat is not hungry, good at summing up experience in failure. Evaluation of student self-assessment, peer assessment based, instructor supervision.

On the basis of fully absorb and learn the tradition of physical education curriculum evaluation, we should pay attention to individual students as the main frame of reference, to an integrated assessment of the innovative spirit and practical ability to target direction. Method of evaluation should not be a single, should be diversified. So that every student has the potential to develop and play to form self-learning, self-training, self-education of internal motivation mechanism to promote the formation of students' active within the required education, the development of personality and comprehensively improve the quality of students, have a positive role to achieve quality education and "health first" dual goals.

\section{Determine the Proportion of the Evaluation Content Index}

Using Delphi method, make college sports expert 10 people (including 8 professors, associate professors and 2) 5 indicators for evaluation of physical education curriculum content sorted by importance. Sort results of quantitative calculation expert analysis to calculate the proportion of evaluation: the physical health $0.2,0.1$ basics, 0.3 basic skills, learning attitude $0.2,0.2$ affective expression and spirit of cooperation. The above results, a second round of survey findings are as follows: 10 experts completely agree with the above result of eight people, accounting for $80 \%$. It can be considered that the determination of the proportion of five indicators, can be established. In order to calculate the terms of the second decimal rounding [5].

\section{Conclusions}

Physical performance evaluation system has a very clear role in guiding and can directly affect students' values and direction of development of sports. Sports teaching process is an important part of its role in the sports teaching process and it is multifaceted, whole control and regulate the sport teaching objectives, the process of teaching activities. Therefore, building a system that can promote overall development of students, student course evaluation system to promote lifelong physical thinking school sports is an important research topic. From the above analysis, we can draw the conclusions as following 5 parts.

(1) Evaluation to determine the proportion of new university sports courses, namely: Physical Health 0.2 , the basics of $0.1,0.3$ basic skills, learning attitude $0.2,0.2$ affective expression and spirit of cooperation.

(2) Proposed course of study in college sports integrated score.

(3) Presented quantitatively College Sports Curriculum Assessment methods.

(4) Proposal evaluation system to determine the ultimate sports scores, the implementation of scoring system to quantify the upcoming performance evaluation scores, home converted into excellent (90-100 points), good (75 to 89 points), pass (60 to 74 points), fail (60 points or less) 4 levels.

(5) As the "Student Healthy Standard" test is conducted once a school year, and sports performance assessment is to be assessed each semester, therefore recommended to test the next semester, last semester with a medical clinic and a corresponding physical indicators of project testing and scoring.

\section{References}

[1] Ding Xu: Journal of Anhui Sports Science, Vo1. 14 (2008) No.5, p. 63-67.

[2] Xu Yan: Journal of Physical Education, Vo1. 1 (2004) No.1, p. 47-51.

[3] Wu Keqi: Journal of Physical Education, Vo1. 4 (2002) No.1, p. 68-75.

[4] Dong Zhelin:Journal of Wuhan Sports Science, Vo1. 1 (1999) No.6, p. 576-581.

[5] Wensheng Zhou, Dao Son, C.-C Jay Kuo: Information of Sports, Vo1. 8 (2002) No.27, p. 559-586. 